\title{
On the Differences of Family Education between Chinese and American Families: A Case Study of The Pursuit of Happyness and Ocean Heaven
}

\begin{abstract}
Zheyun Zhou ${ }^{1, a}$
${ }^{1}$ GUILIN UNIVERSITY

a193142931@qq.com

ABSTRACT

The movie is not only the art form of life, but also the artistic expression of life. Different ideologies reflect on the social lives of movies of different countries. The movie is a good way to observe cultural differences, including family education differences, between Chinese and American families and analyze them. The differences were brought up by different social backgrounds while common ground exists. The author tries to analyze the differences between Chinese and American family education and the reasons from three aspects: family individual difference, social form difference, and educational convention of Chinese and America through classic movies - The Pursuit of Happyness and Ocean Heaven. The author also talks about the impact brought by different family education and the historical background that cause different education methods between Chinese and American families. In order to achieve the research goal, the author uses content analysis and comparative analysis.
\end{abstract}

Keywords: Chinese-American Differences, Family Education, Movie Analysis

\section{INTRODUCTION}

Due to obvious differences in ideology and history development, Chinese and Americans varied in family education. Chinese and American cultures have different social forms and concepts due to different regional civilizations. And family education refers to the educational influence that parents have on the growth and development of their children during family interaction, and it is also an important part of education throughout one's whole life. The American movie The Pursuit of Happyness and the Chinese movie Ocean Heaven have presented it in a certain way. Both of the stories start with the father takes care of the son single-handedly. These two movies share the same rhetorical structure, therefore, comparable.

The Pursuit of Happyness talks about the father, a black man named Chris Gardner, who works his way up and becomes a well-known stockbroker. In the beginning, Gardner has invested heavily in a device known as a "bone density scanner". He feels like he has it made selling these devices. However, they do not sell well as they are marginally better than x-ray at a much higher price. As Gardner works to make ends meet, his wife leaves him and he loses his apartment. Forced to live out in the streets with his son, Gardner continues to sell bone density scanners while concurrently taking on an unpaid internship as a stockbroker, with slim chances for advancement to a paid position. Before he can receive his salary, he needs to outshine the competition through 6 months of training and to sell his devices to stay afloat. But in front of the children, he will always be an indomitable father. Even if he is so embarrassed that he has to spend the night at the subway station, he has to play a game of avoiding dinosaurs with the child. His son is also very sensible and has never bothered him, and has become the driving force for him to climb up after falling down time and time again. He eventually becomes the one he always dream to be $-\mathrm{a}$ man that can provide a comfortable life to one he loves, in this case, his son.

Ocean Heaven is a story of a father who works as a plumber and his autistic son. The mother passed away when her son, Dafu, was little. She couldn't bear the fact that her son is autistic. The father is diagnosed with cancer not long after his son's adulthood. The father was diagnosed with advanced liver cancer and only a few months left in his life. How to set up a life of great blessing has become a big deal for him day and night. Then he teaches Dafu how to survive on his own, and 
also asks the people around him and the welfare organization to take care of him. At the end of the movie, before his death, the father pretends to be a sea turtle and be with Dafu, hoping Dafu feels less lonely and understands that even though he won't be here physically any longer but as long as he sees a sea turtle, he's there with Dafu, Dafu didn't know what does this mean, but he keeps chasing the "sea turtle" that symbolizes his father and finds his heaven in the end.

Both of the movies tell the story of fathers playing the mother's role of educating kids in their family while being a father as well. All embody a strong fatherly love. Because of individual differences, different education methods were presented, which sumps up different education characteristics between Chinese and American families.

\section{DIFFERENCE IN FAMILY BACKGROUND}

In The Pursuit of Happyness, the son, Christopher Jr., grows up with a healthy personality and graduates on time even though his mother leaves him and his father is broke. Christopher Jr. goes to an education organization with very limited resources, but he still manages to finish his study and live as his peers do. If everything goes his way, he might even reach a higher goal. Under this circumstance, Gardner plays a role in encouraging and leading his son to accomplish his dream and be his son's companion. He believes his son has a bright future. For example, Christopher Jr. likes playing basketball and wants to be a professional basketball player. But Gardner doesn't have faith in him. Christopher Jr. feels upset when the words reach his ears. His father, therefore, says to him “don't let anyone tell you what you can't do, not even me all right?'He said it because Christopher Jr. reminds him of the bumping road he had walked through. "You got a dream, you gotta protect it. People can't do something themselves, they wanna tell you you can't do it. If you want something, go get it. "In addition, Gardner has nothing but a healthy body, which allows him to keep reaching his goal. What Gardner had experienced reflects on his education to his son to keep working until he achieves his goal. It shows that in order to realize personal dreams and love for his son, an ordinary person actively overcomes difficulties under nightmarish adversity and difficult conditions, never gives up, stays positive and optimistic,still fulfilling the responsibilities of a father, and finally realized the dream through personal struggle and experienced the joy of success.

In Ocean Heaven, however, the autistic son, Dafu, had taken the compulsory education, but he still can't live a normal life due to his mental illness. His father wants him not much but to be able to cook, to go by car, and to pay for himself. As a father, his responsibility is to find a good foster family to take care of his son.
" That really sent Dafu to the door of some orphanage, and they wouldn't refuse it. Then if they really don't accept it, or if they accept it, whether they can support him for a lifetime, I don't know before I leave." $\mathrm{He}$ seeks welfare organizations one after one, asking one of his superiors to give his son a job after he passing away. In hope of his son will be able to live his life. In the beginning, he can take care of everything for his autistic son, but when he finds out that his life's end is right in front of him, he gets grumpier to Dafu as his death is near because he's worry about his son. But his wish gets fulfilled after his death. Father taught son the simplest of boiling water, beating eggs, crossing the road, getting on and off the bus, opening the door with the key, and putting on and taking off clothes. He poured his love and patience for his son, so that his 21-year-old son could live on his own after his death. There is a plot. Dad teaches his son how to say "I get off" when the bus arrives. Dad wears a hat and plays the role of a bus attendant. He repeats the name of the station when he gets off the bus over and over again. Under his father's tireless teaching, the son finally learned the simple two words. There are no gorgeous language dialogues and lines expressing the love of the father and the son in the whole movie, which shows the restrainedness of the Chinese. The father comforts himsel "In fact, autism is also quite good, living in your own world, neither lonely nor lonely. Have oneself to accompany oneself to play. Even if outsiders don't understand."

It can be seen that Americans value characteristic development while Chinese value social assimilation from two fathers' differences in life experience, social background, and physics. Even though the family background is not the only reason behind the difference, but it is still an important factor that contributes to family education difference.

\section{DIFFERENCE IN SOCIAL FORMS}

The difference is as obvious in social forms as in family educations.

American capitalism emphasizes individual interests and values. Americans pay attention to individuality, and their values are people-oriented individualism. This is the core of American culture and is also reflected in family education. They emphasize that human beings are independent individuals with reason, dignity and free. Individuals clarify their own needs and goals, and require people to be responsible for their own destiny. They believe that success is in their own hands, and that they are the leader of the whole life. That's the "American dream". "American dream has been the dream of all Americans since 1776. They believe better life comes from hard work and perseverance, which means diligence, courage, creativity, and a determined mind are the reasons for the prospect, not the help from others or higher class". For example, Gardner's wife left 
him because she couldn't stand the distress anymore. She tried to fight for Christopher Jr.'s custody but had to give it up eventually. She didn't reach out to her ex-husband when they got evicted. Gardner had no one by his side, neither could he retrieve his money from his friend he had once helped moving places because it was deemed as debt payment. Americans value individual interests, which is why independence and freedom get promoted in their family education.

Chinese socialism emphasizes collective power and honor for all. That's the "Chinese dream". It is the collective of Chinese ethos and Chinese power. Scenes from Ocean Heaven are the presentation of the Chinese dream. For example, Dafu doesn't have to pay for the groceries because the shop owner is very well aware of his condition; his father finds him a job by begging the superior, who didn't agree at first because he thinks Dafu is not qualified for the job, but give the job to Dafu after his father passed away; a welfare organization takes care of Dafu after his father's death. Human connection is not just about interests, but also about favors and society benefits. Under such circumstances, the father takes care of everything for his son because on the one hand, Dafu is not mature enough and not capable of taking his responsibility; on the other hand, the social background. Dafu's father has utilized all his connections to make sure Dafu doesn't have to suffer when he's gone. He wants Dafu to live a comfortable life. He never wants Dafu to pay him back, he just wants him to be healthy and happy. Chinese pay attention to the people's social value, to link the development of education and family together. This is related to Chinese Confucian culture.

We can feel that there are still big differences in the concept of family education between China and the United States. These differences are caused by many factors.. Each of the family education differs from one another, which also puts a huge impact on the kids from different countries. Dialectical thinking is required when it comes to this.

\section{CHINESE-AMERICAN EDUCATION TRADITION}

America has a rather short founding history in which the Enlightenment had played an important role. The United States is a country of immigrants with little cultural heritage, and is generally affected by multiculturalism and multi-values Therefore, Americans advocate freedom and equality in every aspect, including family education. In American families, parents mainly use an equal way to educate their children. They respect their children's personality and power. In the family, children are treated as independent individuals. Parents and children are equal. For instance, Gardner never criticizes his son for watching too much TV in school. He makes his requirements to teachers about too much TV for the kids directly instead of scolding his son. And when he sees the word "fuck", which is a curse word in English, written on the school gate, he doesn't choose to skip this topic. Unexpectedly, he chooses to discuss it with his son. He first asks who wrote the word, then he asks his son to write down the word and exchanges thoughts on the spelling with his son. This is the western type of education. In addition, they express their feelings to each other as if they're best friends. Christopher Jr. says to his father directly that he is a good father. And Gardner does the same. He doesn't hide his feelings toward his son; he even jokes about his difficulties with his son. They fight together. This is how family education works in western families. The western families think love is something that needs to be expressed constantly. It is important to show your love to the one or ones you love by saying "I love you" or give them praises.

However, the Chinese are much more implicit in expressions. The Chinese are a collectivist spirit, which emphasizes that collective interests are more important than personal interests. They believe that one person's life is related to other people. They also treat their children as their own private property and they believe that they should bear the responsibility of taking care of their children. The children are taught to be subordinate to their parents. For instance, Dafu's father tries to drown them both to death when he found out he has cancer. But Dafu is so good at swimming, he saves them both. The father thinks Dafu cannot live a comfortable life if he's not here takes care of everything for him. That's why he wants to drown themselves. This shows how much father and son are bonded and inseparable in China. It is different in America. Family members will not push his or her idea to the other one. And they seldom express their love to each other. The father doesn't express his difficulties to Dafu when everyone around him knows he's desperately struggling. The father doesn't tell Dafu how much he loves him by mouth, but by being a "sea turtle" always by his side. Dafu does the same. He shows no emotions when his father passed away, but he embraces the sea turtle as if it was his father. It is very touching even without Dafu expressing his love directly toward his father. This is a typical Chinese family where people hold their feelings, whether good or bad, in their hearts. The sentence "I love you" is very simple, but it could weight a thousand pound in the heart. Chinese are very reserved, expressing feelings, especially bad feelings, to others sometimes can be seen as a burden.

\section{ENLIGHTENMENT}

Different values determine the characteristics of family education. Lessons can be drawn from the analysis of family education differences between China 
and America. It is vital for Chinese education reform and the world's education development.

On the one hand, Americans should learn to help each other. American family educations advocate freedom and independence, but as social animals, it is impossible to get things done without others' assistance. It is good to embrace assistance, more or less, from society while keeping independent. American family education is too loose and rational, and lacks a sense of responsibility for supporting parents. American family education should embrace assistance from society while keeping its independence. Promoting collective consciousness in family education keeps kids from being isolated in their social lives.

On the other hand, the Chinese should learn to give more freedom to their kids and teach them to be independent. Chinese parents love spoiling their kids by doing everything for them, which is completely contrary to American parents. Parents' spoiling can easily cause children's personality defects and lose the ability to survive. This kind of education is unreasonable and lacks scientificity. Chinese parents must communication with their children, expresse in the language of praise to encourage their children, increase communication with their children, listen to children's voices. Encouraging kids to take responsibility on their own instead of doing it for them can benefit them more.

\section{CONCLUSION}

In America, parents take the role of a leader instead of a master. They do not decide what their kids should be, nor criticize. They value not only physical growth but also character development.

In China, parents do everything for their kids as if children are untouchable diamonds. They constantly worry about the future of the children.

Family education in both China and America has its advantage and shortage. We should always take the best part from both of it and utilize it to make family education better. But whether parents from China or America, their love for children always are the same. Parents want nothing more but their children to grow up to be a healthy and educated person.

While reflecting on the differences in family education between China and the United States, we must also pass on this attitude of rational comparative analysis. This is a prerequisite for objective rationality. It cannot blindly converge or deny it completely. Integration and complementarity is an attitude of wisdom.

There are many discussions about Chinese and American family education differences, but the core hasn't changed. Only by using the experience of America's outstanding education method for reference can Chinese family education keep moving forward.

\section{REFERENCES}

[1] Li Xin, On the Differences between Chinese and American Family Education from the Perspective of Culture, 2006

[2] Bu Dezhen, Sun Aixue, The Causes of the Differences between Chinese and American Family Education, School of Teachers and Education of Shandong Normal University, Chenzhuang Middle School of Huantai County of Zibo City of Shandong Province, 2008.

[3] Wang Liuhua, Analysis of the Root Causes and Enlightenment of Family Education Differences between China and the United States -- from the Perspective of Chinese Confucian Culture and American Individualism Culture, School of Foreign Languages of Quanzhou Normal University, 2012.

[4] Jin Yanfei, On the Differences of Family Education between China and America, School of International Studies of Zhejiang University, 2011.

[5] Shao Xuan, Zhang Jing, A Study on the Differences between Chinese and American Family Education and Cross-cultural Communication, College of Arts and Science of Northeast Agricultural University, 2010.

[6] Tian Xinyu, A Cross-Cultural Comparison of Family Education Differences between America and China, Beijing Forestry University, 2019.

[7] Huo Caiqiao, Yuan Xinfa, A Comparative Analysis of the Differences of Family Education between China and America, Baoding University, 2015. 